\title{
O olhar desencarnado: jogos de máscaras no cinema de ficção científica
}

João Vitor Resende Leal'

I - USP

São Paulo (SP), Brasil

Resumo: Este artigo busca refletir sobre o trabalho do ator a partir de personagens androides no cinema de ficção científica. Discutiremos como o recorrente motivo do desmascaramento do androide coloca em questão o rosto e o olhar humanos. De A clever dummy (1917) a Blade Runner 2049 (2017), examinaremos algumas das estratégias narrativas e estéticas que transformam o ator em personagem-máquina, atentando também para possíveis origens da figura do androide na cultura ocidental e para alguns de seus desdobramentos na obra dos artistas Otávio Donasci, Tony Oursler e Denis Marleau.

Palavras-chave: androide; rosto; máscara; ator.

Abstract: The disembodied gaze: plays of masks e in science-fiction cinema - This paper examines the actor's performance of android characters in science fiction films. We will I discuss how the recurring motif of the unmasking of the android puts the human face and gaze into question. From A clever dummy (1917) to Blade Runner 2049 (2017), we will I analyze some of the narrative and aesthetic strategies that transform the actor in a machine-like character, also pointing to early manifestations of the figure of the android in Western culture and to some of its recent developments in the work of artists Otávio Donasci, Tony Oursler and Denis Marleau.

Keywords: android; face; mask; actor.

Este artigo pretende investigar a tensão entre homem e máquina - entre o natural e o artificial, o familiar e o estranho - que, materializada na figura do androide ${ }^{1}$, nos permite repensar relações entre identidade e expressão, atuação e performance, rosto e máscara. No decorrer do que propomos aqui como um breve panorama do androide no cinema recuperando algumas de suas origens no imaginário ocidental e apontando para alguns

1 O termo androide, de raízes gregas, diz respeito àquilo que tem a forma exterior (oide) de um ser humano (andro) 
de seus desdobramentos no audiovisual contemporâneo -, buscaremos articular cinema, literatura, teatro, psicanálise e história da arte, a fim de inserir o androide cinematográfico em uma reflexão sobre o rosto e o olhar humanos e, dessa forma, abrir novas perspectivas para o estudo do trabalho do ator e da própria noção de personagem.

Na comédia A clever dummy, dirigida por Herman C. Raymaker para os Estúdios Keystone em 1917, um inventor cria um boneco mecânico em tamanho real tendo como modelo o zelador do prédio onde mora. Por trás da aparência do zelador (interpretado por Ben Turpin), o boneco é um intrincado sistema de engrenagens conectado a um controle remoto no qual os diversos botões indicam as partes móveis e os movimentos possíveis: Braços, Pernas, Dança, Boxe e assim por diante. Essa premissa de ficção científica adquire contornos cômicos quando o zelador assume secretamente o lugar do boneco na esperança de conquistar a atenção da jovem e adorável filha do inventor.

À época da realização do filme, Ben Turpin já era bastante conhecido em Hollywood pelo vigor de suas performances corporais e por um característico bigode - uma espécie de precursor e concorrente, pois, do Vagabundo imortalizado por Charlie Chaplin. Seu maior traço distintivo, contudo, era um acentuado estrabismo, ostentado por ele como sua marca registrada: um artigo da revista Time de 1928 revela que, aceitando o estrabismo como a principal razão de seu sucesso como comediante, Turpin teria contratado um seguro no valor de 100 mil dólares a ser pago caso seus olhos voltassem ao normal (SILVER, 2010).

Em uma cena crucial de $A$ clever dummy, o inventor decide apresentar sua criação a uma dupla de investidores. Ele não se dá conta, todavia, de que é o próprio zelador quem, tendo escondido o boneco, agora responde aos comandos feitos pelo controle remoto. Nesse momento, a performance de Turpin precisa funcionar em dois níveis distintos: ele deve ser convincente como uma criatura mecânica para os demais personagens em cena e, ao mesmo tempo, deixar claro para o espectador que se trata do zelador fingindo ser o boneco. Seus movimentos não podem ser demasiado mecânicos nem demasiado humanos, sob o risco de se dissolver a comicidade da situação. É claro que, dadas as convenções da slapstick comedy, tal distinção entre homem e máquina dispensa grandes sutilezas; ainda assim, a performance de Turpin nos parece precisa, mesclando com êxito a rigidez de movimentos do boneco ao desleixo zombeteiro do zelador. Ao final dessa mesma cena, com os investidores satisfeitos de seu novo negócio, dois close-ups destacam o rosto - e os olhos estrábicos - de Turpin, como que selando um pacto de cumplicidade entre o ator, seu personagem e o público.
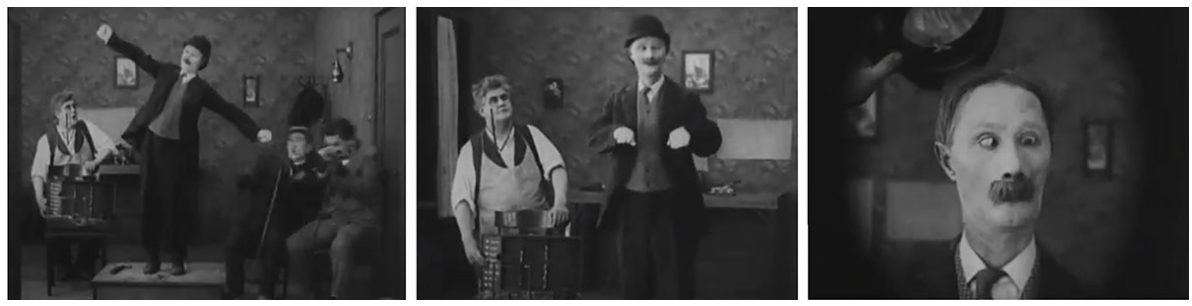

Fig.1. Ben Turpin em A Clever Dummy (1917) 
Essa performance de Turpin nos leva a ver com clareza como a presença em cena de androides representados por atores humanos prontamente levanta questões sobre a natureza e a figura humanas, sobre o que leva uma criatura a ser considerada humana ou inumana. Ao nosso ver, essas questões estão inevitavelmente associadas às técnicas empregadas pelo ator na construção do personagem androide: linguagem corporal, expressão facial e vocal, próteses, maquiagem e figurino são alguns dos recursos que permitem ao ator conferir certa familiaridade a uma criatura mecânica ou, ao contrário, suscitar certa inquietante artificialidade em um corpo humano que, de resto, nos seria familiar.

\section{Corpos estranhos}

A figura do androide pode ser rastreada pelo menos até o mito grego de Pigmalião e Galateia. Conforme contado pelo poeta romano Ovídio (2007 [8 d.C.], p. 252-253), Pigmalião era um escultor que se apaixonou por uma de suas estátuas - Galateia lhe parecia tão bela e pura, como uma autêntica jovem que apenas não se movia por timidez, que ele implorou a Vênus, deusa da beleza e do amor, por uma esposa semelhante a ela. Em um dia de festa, Vênus atendeu seu pedido transformando a estátua em mulher.

É interessante observar, como propõe Victor Stoichita (2011, p. 25-33), que todas as manifestações da metamorfose de Galateia descritas por Ovídio se dão como reações físicas em um cenário háptico de sensualidade a ser desfrutado por Pigmalião: o corpo de Galateia se torna quente e macio como uma cera amolecida sob o sol e, com um polegar, Pigmalião sente o pulso em suas veias. Galateia não demonstra nenhuma motivação, nenhum traço psicológico que a defina; ela se torna humana, mas sua humanidade permanece confinada aos anseios de seu criador. Retrabalhada ao longo de inúmeras narrativas fantásticas², a figura de Galateia se tornou o arquétipo da mulher ideal fabricada à medida do desejo masculino. Mais recentemente, ela também tem sido abordada em perspectivas feministas, pós-gênero e pós-humana (ou trans-humana) como uma figura capaz de reconfigurar as noções habituais de identidade, subjetividade, corporeidade e gênero3 ${ }^{3}$.

À sensualidade de Galateia, podemos opor a monstruosidade da criatura de Frankenstein, que ganha vida a partir de órgãos e tecidos mortos. Em Frankenstein, ou o moderno Prometeu (SHELLEY, 1818), a tecnologia do mundo moderno substitui a intervenção da deusa Vênus e a criatura, como uma máquina, precisa apenas de uma faísca elétrica para se animar. A racionalidade tecnológica que impulsiona o romance de Shelley, fermentada por avanços na medicina e pela segunda revolução industrial, aponta

2 A androide feminina é central em obras como $O$ homem de areia (E.T.A. Hoffmann, 1817) e A Eva futura (Villiers de I'Isle-Adam, 1886), que apresentam autômatos como mulheres ideais. Já em O castelo dos Cárpatos (Júlio Verne, 1892) e A invenção de Morel (Adolfo Bioy Casares, 1940), a criatura mecânica é substituída por projeções audiovisuais que presentificam as figuras femininas por quem os protagonistas se apaixonam.

3 Essa apreensão da androide, defendida por Donna Haraway no influente "Manifesto ciborgue" publicado em 1985 (HARAWAY, 2000), foi mais recentemente desenvolvida em obras como Death 24x a second (MULVEY, 2006) e O corpo mecânico feminino (MONTEIRO, 2016). 
para a ideia de que o corpo humano funcionaria exatamente como uma máquina, com peças e partes que, perfeitamente articuladas, conferem autonomia ao todo. Nas artes visuais, essa concepção maquínica do corpo não está distante, por exemplo, das pesquisas cronofotográficas de Marey e Muybridge e de pinturas modernistas como o Nu descendo as escadas $n^{\circ} 2$ de Duchamp (1912) - obras que investigam o movimento corporal por meio de uma metódica multiplicação-decomposição-sobreposição das figuras.
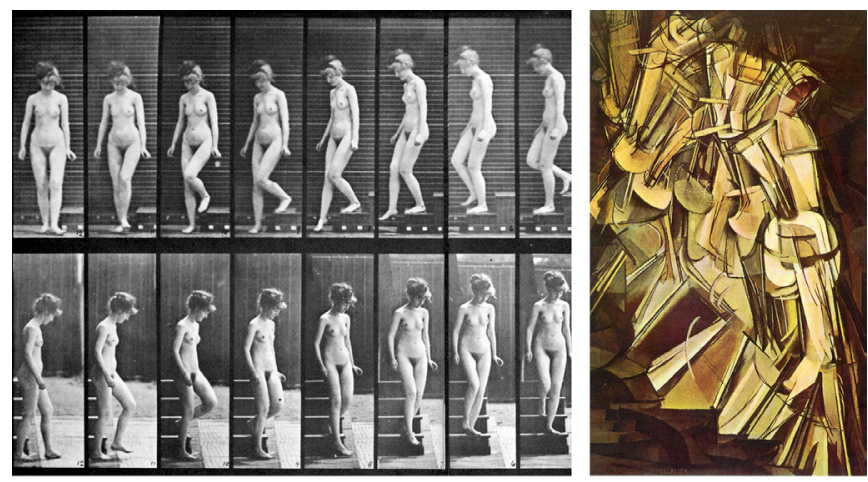

Fig.2. Mulher descendo as escadas (Muybridge, circa 1885)

Fig.3. Nu descendo as escadas $n^{\circ} 2$ (Duchamp, 1912).

A virada para o século XX também foi palco de mudanças profundas no entendimento das percepções e emoções humanas. Em um breve artigo de 1906, Ernst Jentsch buscou compreender a desagradável sensação provocada pela incerteza acerca da natureza física de certos objetos, como bonecos de cera e autômatos - objetos que, por sua aparência natural ou pela perfeição dos mecanismos que os animam, parecem estar vivos inclusive aos olhos daqueles cientes de sua artificialidade (JENTSCH, 1997 [1906], p. 9-12). Essa sensação, batizada inquietante (Unheimlich), foi retomada por Sigmund Freud, que a definiu não exatamente como uma incerteza diante daquilo que ainda nos é desconhecido, mas, ao contrário, como uma reação psicológica diante de algo que, apesar de "assustador", invariavelmente "remonta ao que é há muito conhecido, ao bastante familiar" (FREUD, 2010 [1919], p. 249).

Apesar das divergências ${ }^{4}$, tanto Freud quanto Jentsch se valem do inquietante para refletir sobre a experiência da morte, as manifestações de supostos "poderes ocultos" (magia, feitiçaria) e o incorrigível animismo da imaginação humana, tantas vezes explorado em criações artísticas, que tende a conferir vida a figuras e objetos inanimados. É de se lamentar, portanto, que nenhum dos dois autores tenha estendido suas preocupações ao cinema, onde a impressão de movimento gerada pela sucessão de imagens estáticas logo

4 A grande crítica de Freud a Jentsch diz respeito à interpretação do conto O homem de areia, de E.T.A. Hoffmann (1817): enquanto Jentsch associa o efeito inquietante a Olímpia, autômato por quem o protagonista Natanael se apaixona, Freud entende que o inquietante é suscitado, antes, pelo vendedor Coppola, em quem Natanael reconhece um velho amigo de seu pai. Ver MULVEY, 2006, p. 37-50. 
se provou capaz de animar as mais estranhas criaturas e onde androides de todos os tipos parecem ter encontrado seu habitat natural ${ }^{5}$.

\section{O olhar do androide}

Um dos filmes que melhor representa a concepção moderna do corpo humano como máquina, realizado uma década após A clever dummy e uma década antes do incontornável Tempos modernos de Chaplin (Modern times, 1936), é Metropolis (LANG, 1927). Em um futuro distópico, a população de Metropolis se encontra dividida entre uma elite industrial em suas torres majestosas e uma massa de operários relegada ao mundo subterrâneo. Nessa divisão social, que o filme reproduz para melhor criticar, logo fica claro que os corpos dos operários são pouco mais do que peças vitais para o funcionamento da grande máquina que abastece a cidade em energia elétrica - corpos rigorosamente disciplinados, "submetidos aos ritmos de produção das máquinas" (SIQUEIRA, 2002, p. 56). Contudo, com a liderança da rebelde Maria (Brigitte Helm), os habitantes do mundo subterrâneo esboçam, aos poucos, uma reação contra a elite opressora.
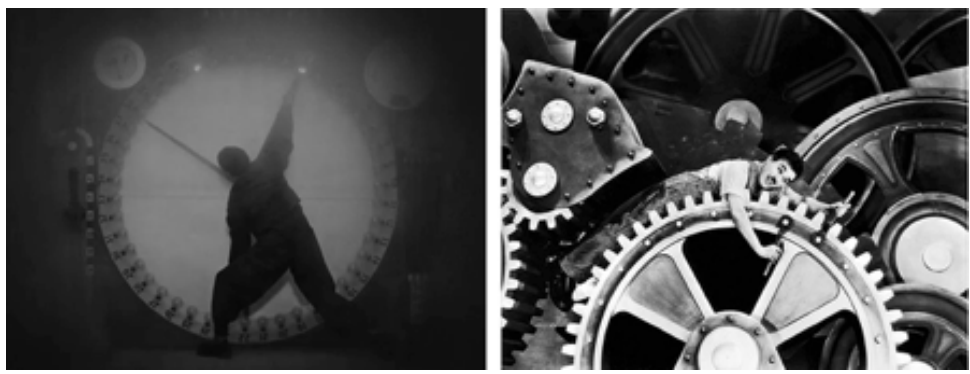

Fig.4. O operário-máquina em Metropolis (1927) Fig.5. Tempos modernos (1936).

A fim de corromper os operários rebeldes, o industrial que governa a cidade sequestra Maria, substituindo-a por uma androide idêntica a ela. Brigitte Helm interpreta as personagens de modos distintos: enquanto Maria é uma figura delicada e inocente, de gestos lentos e poses angelicais, seu duplo mecânico é incisivo e histriônico. Além disso, apenas o rímel preto ao redor dos olhos permite identificar a androide, como pode ser notado em detalhe em uma cena crucial: quando o industrial ordena que a liderança de Maria seja desvirtuada, a androide expressa seu consentimento com uma piscadela. Nesse instante, filmado em close-up, o olhar de Brigitte Helm sintetiza a ambivalência essencial da personagem: trata-se de uma máquina, capaz de executar as ordens mais

5 J.P. Telotte observa que os primeiros filmes de ficção científica com androides foram realizados por James Stuart Blackton para a Vitagraph em 1907, e que o gênero logo se consolidou como um dos mais populares do primeiro cinema (TELOTTE, 1995, p. 57). 
perversas sem questionamento, mas uma máquina que compreende e domina as mais sutis expressões humanas.
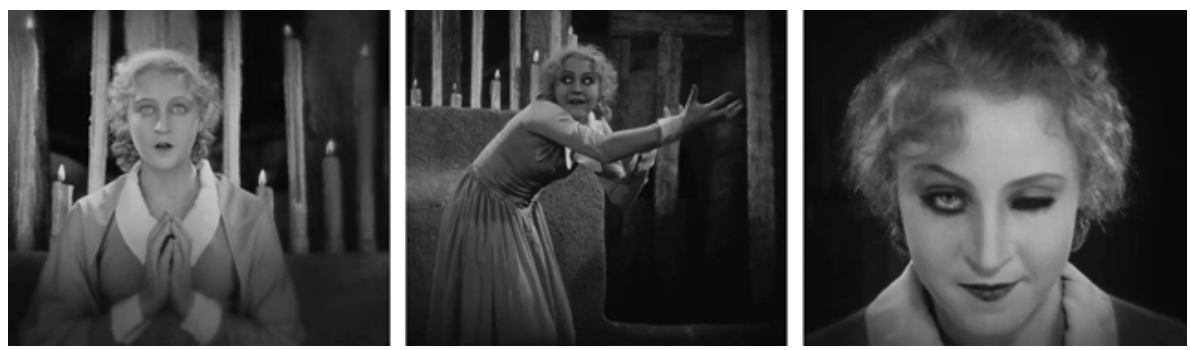

Fig. 6. Brigitte Helm como Maria (esquerda) e a androide (centro e direita) em Metropolis (1927).

A fisicalidade do personagem androide, evidente nas composições de Turpin e Helm vistas até aqui, são frequentemente destacadas no cinema de ficção científica por meio, por exemplo, da dança - a própria Brigitte Helm realiza uma dança erótica em uma sequência de sonho de Metropolis, e filmes recentes como Soldado do futuro (The machine, Caradog James, 2013) e Ex-machina (Alex Garland, 2015) apresentam inesperados números musicais com androides dançantes. A plasticidade dos corpos se torna ainda mais evidente à medida em que os androides se fazem multiplicáveis ou intercambiáveis - corpos indiferenciados, por vezes onipresentes ou indestrutíveis e, por isso mesmo, descartáveis, como os corpos invadidos pelos Vampiros de almas (Invasion of the body snatchers, Don Siegel, 1956) ou pela criatura alienígena de Enigma de outro mundo (The thing, John Carpenter, 1982), ou como os inúmeros Agente Smith (Hugo Weaving) em Matrix (Lana e Lilly Wachowski, 1999).
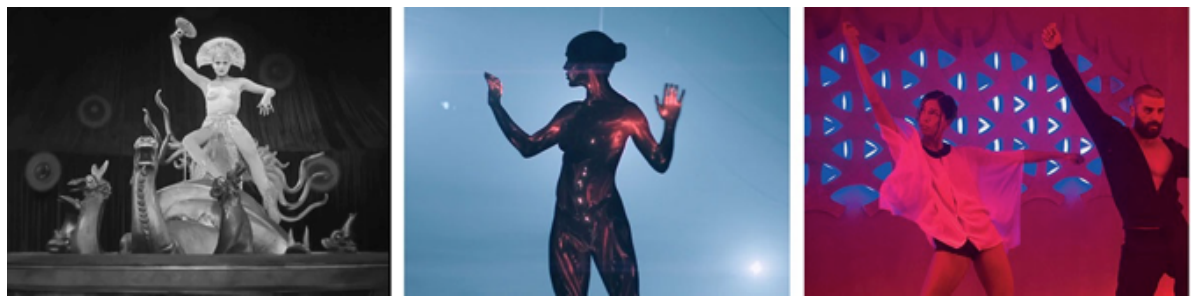

Fig.7. Brigitte Helm em Metropolis (1927). Fig.8. Caity Lotz em Soldado do futuro (2013). Fig. 9. Sonoya Mizuno em Ex-machina (2015).

No entanto, mais do que a construção corporal dos personagens, o que nos interessa aqui é reparar que, enquanto o corpo do androide frequentemente cede aos mais diversos exercícios performáticos e plásticos, seu rosto parece oferecer maior resistência às deformações e desfigurações impostas pelas tramas narrativas, resguardando uma singularidade inquietantemente humana. Assim, mesmo após ter seu corpo destruído, 
a cabeça do androide Ash (Ian Holm) sobrevive em Alien (Ridley Scott, 1979), assim como a de Bishop (Lance Henriksen) em Alien 3 (David Fincher, 1992): a artificialidade dos corpos parece ser, pois, sublimada pela vivacidade da expressão facial.
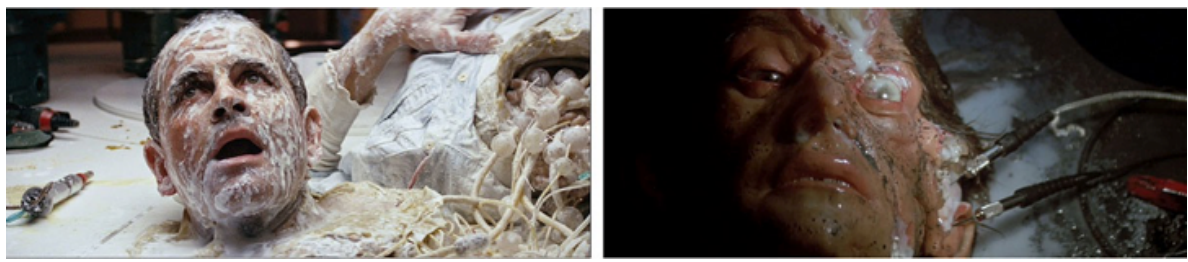

Fig. 10. Ian Holm em Alien (1979).

Fig.11. Lance Henriksen em Alien 3 (1992).

Desse rosto sobrevivente, destacam-se os olhos do personagem androide - e basta um único olho em 2001: uma odisseia no espaço (2001: a space odyssey, KUBRICK, 1968), um único ponto de luz vermelha para personificar o sistema de inteligência artificial HAL-9000, que visa eliminar a tripulação humana, a fim de melhor cumprir sua missão. De certo modo, todo o drama do androide cinematográfico se encontra atravessado por estratégias de figuração do olhar.

Em Blade Runner (SCOTT, 1982), por exemplo, as criaturas chamadas replicantes, fabricadas para auxiliar na colonização de novos planetas, se expressam - e choram e sangram - exatamente como os humanos que as perseguem. Sua artificialidade só pode ser aferida através de uma espécie de polígrafo, um aparelho que detecta variações mínimas em suas retinas. A fim de distingui-los dos humanos, os replicantes possuem olhos com um brilho opaco, como superfícies espelhadas - olhos que rebatem nosso olhar, negando acesso à suposta subjetividade do personagem. Essa preocupação temática é por diversas vezes reiterada: o filme tem início com o close-up de um globo ocular - assim como a sequência Blade Runner 2049 (VILLENEUVE, 2017) - e, ao final, o replicante Roy Batty (Rutger Hauer), que se julga um ser humano aperfeiçoado e se mostra mais emotivo que os próprios humanos, se vinga de seu criador justamente perfurando-Ihe os olhos.
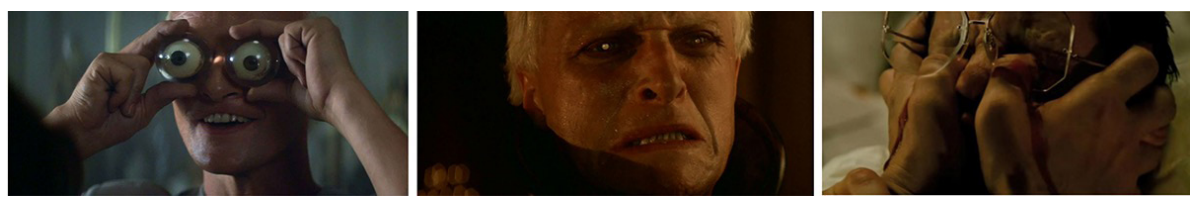

Fig.12. Rutger Hauer em Blade Runner (1982)

\section{Os movimentos da alma}

Leitores de retina capazes de revelar a personalidade, como o polígrafo de Blade Runner, parecem um sonho antigo da cultura ocidental. A ideia de que os olhos exprimiriam 
a essência e os sentimentos mais profundos do indivíduo, difundida desde o Renascimento, parece não ter perdido sua força. Mais do que por gestos ou palavras, é através dos olhos que expressamos "os movimentos da alma", argumenta Alberti em seu célebre tratado De Pictura, de 1435 (apud BREDEKAMP, 2015, p. 278). De modo semelhante, o fisionomista italiano Giambattista della Porta escreve em sua Fisionomia humana de 1586 que os olhos são "a alma do rosto" e "as portas da alma" (apud COURTINE; HAROCHE, 2016, p. 70), e o filósofo francês Marin Cureau de la Chambre afirma em $A$ arte de conhecer os homens, de 1660, que o verdadeiro propósito da natureza para nossos olhos é poder nos desmentir sempre que faltamos com a verdade (apud COURTINE; HAROCHE, 2016, p. 31).

Em cinema, o close-up veio reavivar essa ideia. Para Béla Balázs, o rosto em close-up, isolado no espaço e no tempo, "não é mais uma forma de carne e sangue, mas uma expressão, isto é, um sentimento, um estado de espírito, uma intenção, um pensamento" (BALÁZS, 2011 [1948], p. 71); o cinema teria então verdadeiramente descoberto o rosto humano e, com ele, "as tragédias humanas mais profundas" (BALÁZS, 2011 [1948], p. 76). Assim como o conceito de fotogenia, desenvolvido nos anos 1920 por autores-cineastas como Jean Epstein e Louis Delluc, a noção de fisionomia defendida por Balázs pressupõe uma verdade sublime a ser revelada na/pela imagem cinematográfica ${ }^{6}$. Dessa forma, enquanto a essência do indivíduo emerge em seu rosto, a verdade desse rosto só pode, por sua vez, ser atingida no close-up. A força de tal pressuposto fez com que, nos termos de Jacques Aumont, o cinema naturalista (ou, ao menos, o cinema hollywoodiano) jamais tenha levado adiante uma estética que privilegiasse de fato os corpos dos atores - por mais ágeis, bem treinados, bem cuidados e bem vestidos que sejam, os corpos tendem a passar despercebidos; é o rosto do ator que concentra o essencial de seu trabalho (AUMONT, 1992, p. 50).

A abordagem do rosto sugerida aqui não deve ser confundida com uma tentativa de interpretar expressões faciais, decifrar personalidades, sentimentos e intenções a partir de tal formato de nariz ou de tal contração da boca - como tantas vezes tentaram, sem sucesso, os adeptos de disciplinas caducas como a fisiognomonia ou a frenologia ${ }^{7}$. Desconfiamos, como faz Noa Steimatsky, que essa leitura das expressões faciais é tão consistente, de um ponto de vista científico, quanto à revelação do futuro na palma de uma mão - o poder do rosto está menos naquilo que ele supostamente expressa do que em sua recusa a se entregar por completo às descrições, discursos e interpretações que fazemos dele (STEIMATSKY, 2017, p. 21). Dessa forma, preferimos tomá-lo como

6 Apesar das nuances que distinguem a fisionomia da fotogenia, ambas entendem o cinema como um "operador sistemático da verdade que apenas submete as coisas a seu poder mágico, indescritível, de revelação. Se a fotogenia é um outro nome desse poder mágico, a fisionomia é uma de suas encarnações sensíveis" (AUMONT, 1992, p. 97-98).

7 Apesar do descrédito da fisionomonia e da frenologia, Hans Belting as toma como precursores da atual neurologia, que substitui o interesse pelos traços faciais e pelas proporções do crânio por um interesse pela morfologia do cérebro humano (BELTING, 2017, p. 8). Os estudos fisionômicos também têm alimentado análises relevantes sobre a prática do close-up na fotografia (FABER, 2014) e sobre as estratégias de criação de sentido do jogo atoral no cinema (MACIEL GUIMARÃES, 2016). 
uma imagem que converge para si - ou, mais especificamente, para seus olhos ${ }^{8}$ - o olhar de seu interlocutor ou espectador. Essa imagem pode eventualmente ser legível e interpretável, de fato, mas as possíveis leituras e interpretações estão, aqui, além de nosso interesse.

Se o estrabismo de Ben Turpin e a piscadela de Brigitte Helm já insinuavam algo na fronteira entre o natural e o artificial a ser decifrado no olhar do androide, exemplares mais recentes do cinema de ficção científica, beneficiados por avanços técnicos na maquiagem e nos efeitos especiais, buscam explorar o efeito inquietante nos extremos do horror, do melodrama e do suspense. Com isso, o desmascaramento literal para revelação dos olhos verdadeiros do personagem androide se tornou um momento de considerável reflexividade e intensidade dramática, além de um recorrente motivo visual em filmes do gênero.

Em uma cena de O exterminador do futuro (The terminator, CAMERON, 1984), por exemplo, o androide assassino interpretado por Arnold Schwarzenegger precisa reparar um grave ferimento em seu rosto. Impassível diante de um espelho, ele extrai lentamente o olho lesado e, em seguida, enxuga o interior da órbita vazia com uma toalha. Em um corte, a câmera assume a posição do espelho, colocando personagem e espectador face a face: vemos então que, por trás do rosto de aspecto humano, há um olho mecânico, um globo vermelho que nos é mostrado em close-up preenchendo inteiramente o quadro. A fotografia escura, os ruídos da trilha sonora e a lentidão inexpressiva de Schwarzenegger (que quase se confunde com o dublê mecânico que o substitui nos planos frontais) contribuem para uma atmosfera de tensão que só se dissipa quando o androide, tendo enfim concluído a operação, recobre seu rosto com uma nova máscara: um par de óculos escuros que o permitirá circular novamente em meio aos humanos.
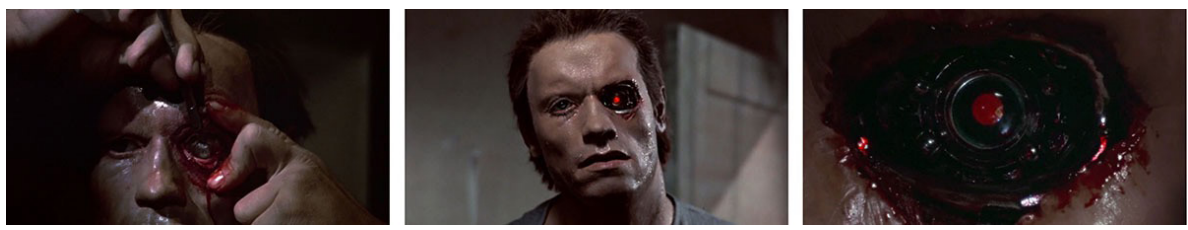

Fig.13. Arnold Schwarzenegger em O exterminador do futuro (1984).

Em outro exemplo, David (Haley Joel Osment), o androide de A.I. Inteligência artificial (A.I. Artificial intelligence, SPIELBERG, 2001), deseja se tornar uma criança de verdade para conquistar o amor de sua humana adotiva. Antes de realizar seu desejo, contudo, ele será confrontado por sua própria artificialidade ao descobrir que seu rosto é uma máscara high-tech produzida em massa. A cena da descoberta explora o motivo visual do desmascaramento de forma categórica: vemos David (e ele nos vê, sem jamais piscar) através das órbitas vazias de uma máscara idêntica a seu rosto.

8 O entendimento de que os olhos são o centro gravitacional do rosto seria um segredo bem conhecido do cinema de animação: "Uma ilustração mal feita ou mal posicionada é aceitável para um braço ou perna, mas nunca para um olho. Como disse Walt Disney, o público está atento aos olhos, e é neles que devemos concentrar nosso tempo e dinheiro para criar um personagem convincente (THOMAS; JOHNSON apud AUMONT, 1992, p. 56). 
Por fim, em um último encontro oportuno entre um rosto e máscara que o constitui, a androide Ava (Alicia Vikander) de Ex-machina (GARLAND, 2015) só interrompe a fuga de seu cativeiro para admirar, exposta em uma parede, a série de máscaras ritualísticas e teatrais que culmina em uma réplica de seu próprio rosto.
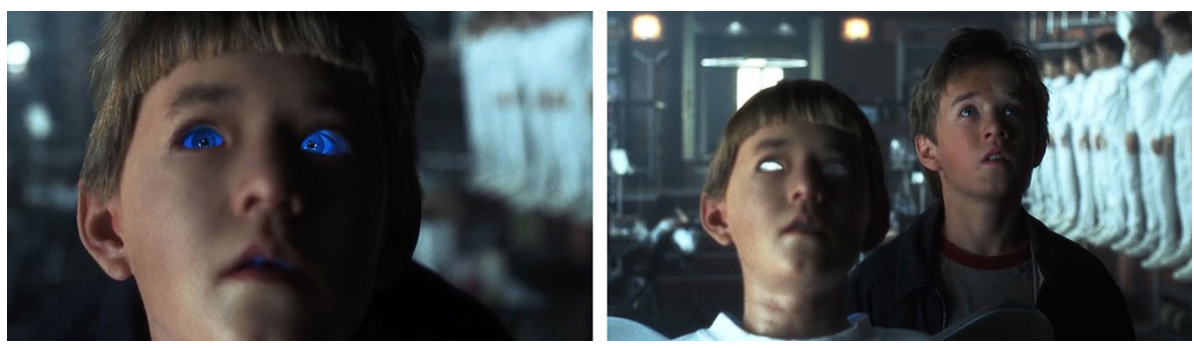

Fig.14. Haley Joel Osment I.A. Inteligência artificial (2001).
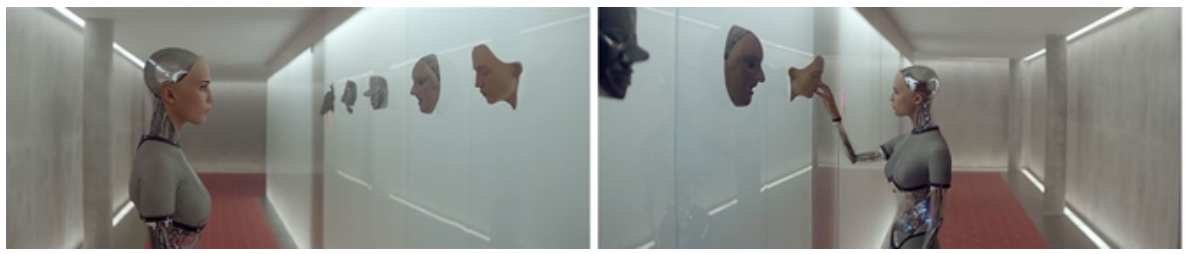

Fig.15. Alicia Vikander em Ex-machina (2015).

\section{Jogos de máscaras}

Atuar sempre foi aderir a um jogo de máscaras, literais ou metafóricas; o que o personagem androide faz é demonstrar o quão intensa essa experiência pode ser. As dissociações entre máscara, rosto e olhos operada pelo androide trazem à tona uma espécie de olhar desencarnado, subitamente inquietante. Ao revelar o olhar humano por trás de uma máscara sintética ou, ao contrário, ao mostrar olhos sintéticos que espiam através de um rosto humano, o androide cinematográfico violaria "a experiência fundamental de nossos rostos":

A ambiguidade entre rosto e máscara se torna imediatamente visível quando a vívida interação entre o olhar e a expressão facial é perturbada ou interrompida. [...] Quando nos encontramos confinados nesse olhar desencarnado de um rosto, somos incapazes de qualquer troca de olhares - incapazes de exercer essa ação que constitui a experiência fundamental de nossos rostos. [...] A expressão facial é, aqui, insignificante; o rosto verdadeiro se congela em uma máscara sempre que o olhar vivo se esconde de nós (BELTING, 2017, p. 7). 
Os jogos de máscaras propostos pelo personagem androide no cinema de ficção científica desafiam o ator a concentrar, em um mesmo rosto e no instante de uma mesma performance, identidades ou personalidades distintas, muitas vezes conflituosas. Assim, o androide cinematográfico demonstra, tanto quanto os papéis múltiplos (em que um ator representa vários personagens ou vários atores representam o mesmo personagem no mesmo filme), a vocação do cinema para romper com o pressuposto que atribui a cada corpo uma única identidade individual. Como sugere Hans Wulff, "nenhuma arte pode associar um mesmo corpo a diferentes pessoas com a mesma liberdade que o cinema" (WULFF, 1997, p. 15). Dito de outro modo, o androide cinematográfico parece satisfazer o que Nicole Brenez entende como a verdadeira especificidade do cinema: a aposta no "génie du lien", na engenhosidade das associações, muito mais do que o estabelecimento de entidades (BRENEZ, 1998, p. 189). De Galateia a Mira Killian (Scarlett Johansson), a androide com cérebro humano de $A$ vigilante do amanhã (Chost in the shell, SANDERS, 2017), da criatura de Frankenstein a Alex Murphy (Peter Weller), o policial amnésico transformado em máquina de RoboCop (VERHOEVEN, 1987), o que está em questão são diferentes modos de se habitar um mesmo corpo e, em um close-up, diferentes máscaras a se encarar em um mesmo rosto, resquícios de diferentes personalidades em um mesmo olhar.
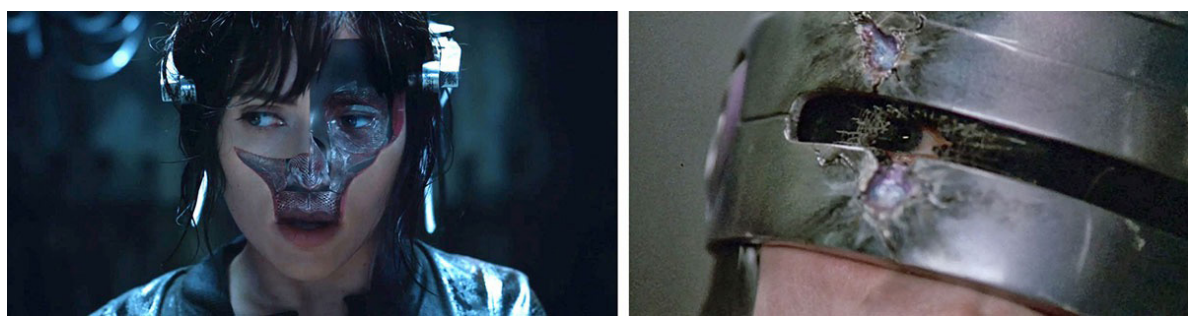

Fig.16. AScarlett Johansson em A vigilante do amanhã (2017)

Fig.17. Peter Weller em RoboCop (1987)

Para além do androide cinematográfico, podemos perceber uma investida no efeito inquietante de representações faciais no recurso a máscaras videográficas nas artes plásticas e no teatro. Basicamente uma performance facial capturada em vídeo para ser projetada sobre uma máscara branca, um boneco ou uma escultura, a máscara videográfica "funciona como uma pele que reveste perfeitamente as formas da máscara", produzindo, por vezes, "uma realidade tão intensa quanto aquela do mundo físico" (ISAACSSON, 2010, p. 31; 34). O vigor da criatura forjada pela máscara videográfica é tal que ela parece bastar por sua própria presença ${ }^{9}$ - estamos ainda mais distantes da órbita da narratologia, da construção de personagens como pessoas fictícias, definidas por qualidades psicológicas

9 Tomamos a noção de presença no sentido proposto por Hans Ulrich Gumbrecht: "Se atribuirmos sentido a alguma coisa presente, isto é, se formarmos uma ideia do que essa coisa pode ser em relação a nós mesmos, parece que atenuamos inevitavelmente o impacto dessa coisa sobre nosso corpo e os nossos sentidos" (GUMBRECHT, 2010, p. 14). 
e motivações a serem desenvolvidas ao longo de uma trama narrativa. Aqui, o que se exige do ator - ou, antes, do performer ${ }^{10}$ - é menos que ele represente um papel e mais que ele produza, auxiliado pelos aparatos de captura e exibição de sons e imagens em movimento, efeitos de presença capazes inclusive de suprir sua própria ausência física no espaço museal ou cênico.

Em uma primeira ocorrência da máscara videográfica, o artista multimídia brasileiro Otávio Donasci desenvolve, desde o início dos anos 1980, séries de "videocriaturas" nas quais monitores de vídeo acoplados às cabeças dos performers funcionam como máscaras animadas. Acentuando a primazia do rosto, o corpo dos performers é coberto por mantos pretos. Concebidas originalmente para apresentações teatrais, as "videocriaturas" também foram empregadas em coreografias de dança, performances e instalações com imagens transmitidas ao vivo.
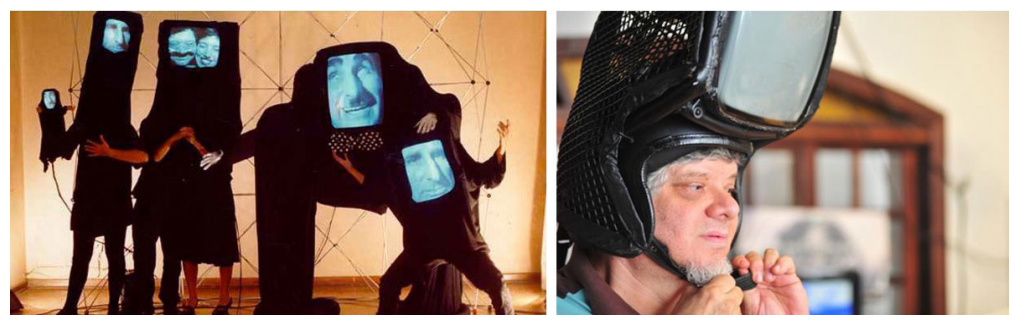

Fig.18. As "videocriaturas" de Otávio Donasci.

O trabalho de Donasci antecipa o do artista americano Tony Oursler que, a partir dos anos 1990, passou a combinar escultura e vídeo em obras que, entre o surrealismo e a psicodelia, isolam e rearranjam elementos do rosto humano. Da boneca de pano com rosto animado de Crying doll (1993) - retrabalhada no videoclipe Where are we now? de David Bowie (2013) - a criaturas disformes de olhos gigantes como Caricature (2002), o trabalho de Oursler opera uma redução radical: o rosto inteiro se torna corpo até que, na instalação Obscura (2014), cada corpo é definido pelos limites de um único olho.
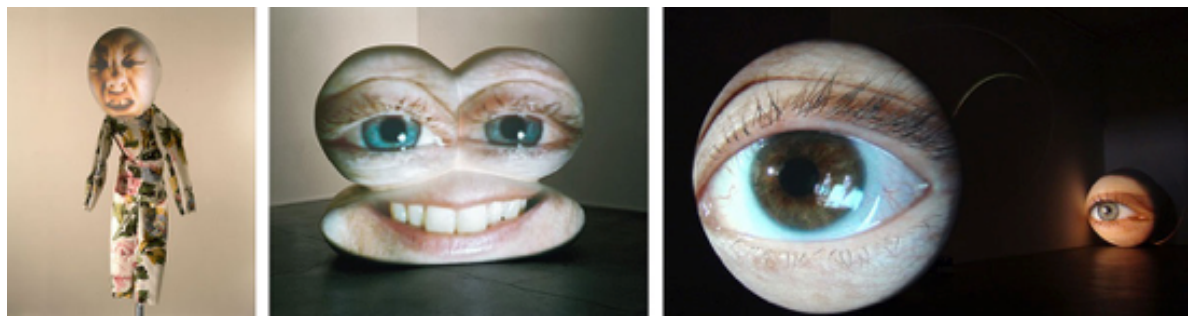

Fig.19. Obras de Tony Oursler: Crying doll (1993), Caricature (2002) e Obscura (2014).

10 Seguimos a distinção entre atuação (acting) e performance trabalhada por Philip Auslander (1997), entendendo que a atuação ocorre sobretudo em prol de uma representação, enquanto a performance liberta o ator de seu personagem ao visar, em primeiro lugar, a imediaticidade de sua presença. Sobre as relações entre atuação/ representação e performance/efeito de presença, ver também FÉRAL, 2008 e LARRUE, 2008. 
No teatro, o diretor canadense Denis Marleau explora o recurso da máscara videográfica desde o final dos anos 1990. Em Les trois derniers jours de Fernando Pessoa (1997), do texto de Antonio Tabucchi, o poeta português encontra seus heterônimos a partir de um dispositivo que coloca o ator face a si mesmo: Paul Savoie, ao vivo no palco, contracena com réplicas de seu próprio rosto projetadas na máscara vestida por outro ator. A precisão dos movimentos e das falas gravadas e proclamadas por Savoie visa a um realismo extremo que, de modo paradoxal, atiça o fantasmagórico: os heterônimos não apenas parecem vivos como são mais vívidos do que o poeta em seu leito de morte. Cinco anos depois, Marleau opta por substituir completamente os atores no palco por máscaras videográficas em Les aveugles (2002), adaptação do texto escrito em 1890 por Maurice Maeterlinck - dramaturgo que, não por acaso, idealizava um teatro de formas simbólicas, sem atores, entendendo que a ausência do homem seria indispensável ao teatro (L'HÉRAULT, 2003, p. 20). Na encenação de Marleau, os doze cegos perdidos na floresta são cabeças flutuantes constituídas por falas e expressões faciais pré-gravadas (performances de Paul Savoie e Céline Bonnier). O resultado é uma imagem marcada por "uma ausência estranhamente presente, como uma nova aura - 'a aparição única de uma coisa distante, por mais perto que ela esteja', como definiu Benjamin" (ASSELIN, 2002, p. 26).
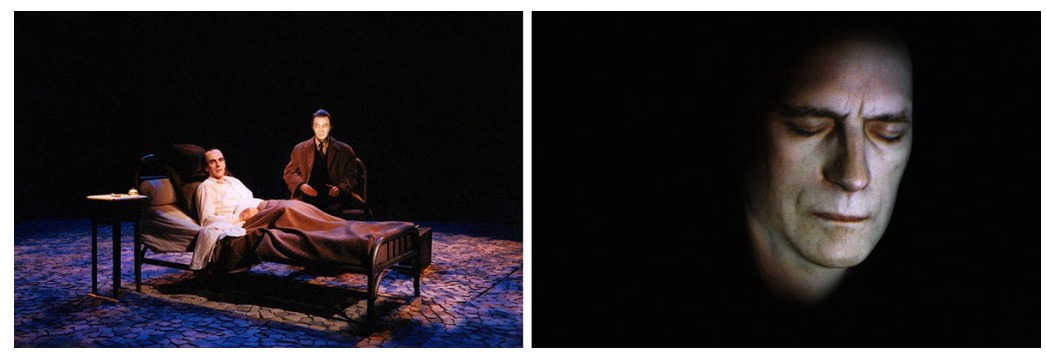

Fig.20. Peças de Denis Marleau: Les Trois Derniers Jours de Fernando Pessoa (1997) e Les Aveugles (2002).

Apesar das inúmeras diferenças entre a obra de Donasci, Oursler e Marleau (e entre os trabalhos singulares que compõem o conjunto da obra de cada um deles), é possível perceber como a máscara videográfica coloca em xeque a representação atoral e aquilo que habitualmente se entende por personagem. As criaturas que emergem das máscaras parecem capazes de sustentar uma ficção indescritível, uma espécie de drama sensorial que vai além (ou permanece aquém) de qualquer trama narrativa - elas dispensam sucessões, progressões, contextos. Como escreveu Balázs, uma vez isolado e ampliado, o rosto "adquire expressão e sentido sem que precisemos imaginar para elas um contexto espacial" (apud STEIMATSKY, 2017, p. 30). A máscara videográfica tensiona a linha normalmente traçada não apenas entre cabeça e rosto - para retomarmos a distinção feita por Deleuze e Guattari (1980) -, mas também a linha que discerne identidade e expressão, atuação e performance, rosto e máscara. Nos passos do personagem androide dos filmes de ficção 
científica, ela não apenas nos leva a repensar as fronteiras entre o orgânico, o mecânico e o virtual, como coloca a tecnologia uma vez mais no lugar da deusa do amor e da beleza que, para o assombro do observador atento, desperta o inanimado.

\section{Conclusão}

Buscamos, ao longo deste artigo, observar como o androide cinematográfico expressa um conflito entre o natural e o artificial, o familiar e o estranho - conflito que, para além das fronteiras da arte, se faz notar em sociedades cada vez mais marcadas pela mecanização dos gestos e a mediatização das relações, assombradas por um iminente triunfo da técnica sobre o afeto e da máquina sobre o indivíduo. Nesse sentido, nos valemos da ficção científica como de um laboratório da imaginação que, ao se deparar repetidas vezes com vestígios de presença humana em criaturas de resto artificiais, não pode se impedir de reformular a questão do que significa, exatamente, ser humano.

Mais especificamente, buscamos desenvolver um percurso que teve, na expressividade do rosto, seu grande objeto de investigação. Entre a vivacidade inesgotável do olhar e o estupor da máscara, o rosto parece reafirmar aqui sua condição de enigma, superfície que ao mesmo tempo revela e oculta, aparência que sugere desejos e sensações, mas insistentemente recusa significados absolutos.

Por fim, ao investirmos em uma multiplicação dos exemplos e abrirmos espaço às máscaras videográficas, esperamos ter avançado também uma reflexão acerca do jogo atoral e da própria noção de personagem - vimos como o personagem se projeta para além da mera representação verossímil de um indivíduo, dando-se sobretudo como encenação de uma presença cuja ambiguidade fundamental (corporal e identitária) é evidenciada pela figura do androide, mas não se restringe, certamente, aos domínios da ficção científica. De fato, tanto o personagem androide dos filmes de ficção científica quanto as criaturas animadas pela máscara videográfica remetem a um estado embrionário de toda e qualquer narrativa, a uma dimensão na qual basta, talvez, um simples movimento, um olhar, para que o familiar venha ser perturbado, uma vez mais, pela estranheza que o constitui.

João Vitor Resende Leal é doutorando (com bolsa FAPESP), do Programa de Pós-Graduação em Meios e Processos Audiovisuais (ECA-USP), em estágio de pesquisa na Université de Montréal.

jv.leal@gmail.com 


\section{Referências}

AMY, M. One to one: conversation avec Tony Oursler. Bruxelas: Éditions Facteur Humain, 2006.

ASSELIN, O. Le fantôme et l'automate: de la reproductibilité technique sur la scène. Alternatives Théâtrales, n. 73-74, p. 24-29, 2002.

AUMONT, J. Du visage au cinéma. Paris: Cahiers du cinéma, 1992.

AUSLANDER, P. From acting to performance: essays in modernism and postmodernism. Londres/ Nova York: Routledge, 1997

BALÁZS, B. Nature et évolution d'un art nouveau [1948]. Paris: Payot \& Rivages, 2011.

BELTING, H. Face and mask: a double history. Princeton/Oxford: Princeton University Press, 2017.

BREDEKAMP, H. Théorie de l'acte d'image. Paris: La Découverte, 2015.

BRENEZ, N. De la figure en général et du corps en particulier. Bruxelas: DeBoeck Université, 1998.

COURTINE, J.-J.; HAROCHE, C. História do rosto: exprimir e calar suas emoções. Petrópolis: Vozes, 2016.

DELeuZE, G; GuATTARI, F. Année zéro: visagéité. In: Mille Plateaux. Paris: Éditions de Minuit, p. 205-234, 1980.

FABER, M. The face under magnifying glass. In: ABBASPOUR, M.; DAFFNER, L. A.; HAMBOURG, M. (Org.). Object-photo. Modern photographs: the Thomas Walther Collection 1909-1949. Nova York: The Museum of Modern Art, 2014. Disponível em <https://www.moma.org/interactives/objectphoto/ assets/essays/Faber.pdf>. Acesso em: 5 nov. 2017.

FÉRAL, J. Por uma poética da performatividade: o teatro performativo. Sala Preta, n. 8, p. 197-210, 2008.

FREUD, S. O inquietante [1919]. In: Sigmund Freud obras completas v. 14: história de uma neurose infantil ("O homem dos lobos"), além do princípio do prazer e outros textos (1917-1920). São Paulo: Companhia das Letas, p. 247-283, 2010.

GUMBRECHT, H. U. Produção de presença: o que o sentido não consegue transmitir. Rio de Janeiro: Contraponto, 2010.

HARAWAY, D. A cyborg manifesto: science, technology and socialist-feminism in the late twentieth century [1985]. In: BELL, D.; KENNEDY, B. (Org.). The cybercultures reader. Londres/Nova York: Routledge, p. 291-324, 2000.

ISAACSSON, M. Desdobramentos do ator e do personagem pela máscara videográfica. Repertório Teatro \& Dança, n. 14, p. 30-36, 2010.

JENTSCH, E. On the psychology of the uncanny [1906]. Angelaki, n. 1, p. 7-16, 1997.

LARRUE, J.-M. Théâtre et intermédialité: une Rencontre Tardive. Intermédialités, n. 12, p. 13-29, 2008.

L'HÉRAULT, P. Mise en scène de l'absence. Imaginaires du numérique, n. 188, p. 20-21, 2003.

MACIEL GUIMARÃES, P. No rosto, lê-se o homem: a fisionomia no cinema. Significação, n. 46, p. 85-105, 2016.

MONTEIRO, M. C. O corpo mecânico feminino: uma poética do transumano. Rio de Janeiro: Garamond/FAPERJ, 2016.

MULVEY, L. Death 24x a second. Londres: Reaktion Books, 2006. 
OVÍDIO. Metamorfoses [8 d.C.]. Lisboa: Cotovia, 2007.

SILVER, A. Ben Turpin's cross-eyes. Time Magazine, $1^{\circ}$ de setembro de 2010. Disponível em: <http:// content.time.com/time/specials/packages/article/0,28804,2015171_2015172_2015093,00.html>. Acesso em: 25 nov. 2017.

SIQUEIRA, D. O corpo no cinema de ficção científica. Logos, n. 9, p. 51-59, 2002.

STEIMATSKY, N. The face on film. Nova York: Oxford University Press, 2017.

STOICHITA, V. O efeito Pigmalião: para uma antropologia histórica dos simulacros. Lisboa: KKYM, 2011.

TELOTTE, J. P. Replications: a robotic history of the science fiction film.Urbana and Chicago: University of Illinois Press, 1995.

WULFF, H. La perception des personnages de film. Iris, n. 24, p. 15-32, 1997.

Artigo recebido em 30/11/2017 e aprovado em 15/08/2018. 